\title{
Perceptions of patients with end-stage kidney disease (ESKD) and their informal caregivers on palliative care as a treatment option: a qualitative study
}

\author{
Catherine Sarfo-Walters ${ }^{1}$ (D) and Edward Appiah Boateng ${ }^{2^{*}}$ (D)
}

\begin{abstract}
Background: Palliative care is increasingly becoming an accepted treatment choice for many individuals diagnosed with end-stage kidney disease (ESKD). Yet, its utilisation is non-existent in many lower- and middle-income countries (LMICs). This study explored the perceptions of individuals with ESKD and their informal caregivers on palliative care as a treatment option for the disease in Ghana.

Methods: This was a phenomenological study, with an in-depth analysis of data collected from nine individuals with ESKD and six informal caregivers through individual, face-to-face semi-structured interviews. The study was conducted in two renal centres within the Kumasi metropolis, Ghana among individuals with ESKD seeking care from both renal centres and their informal caregivers.

Results: Three main themes were derived from this study - motivation for initiating haemodialysis, facing realities of haemodialysis, and considering palliative care. Participants felt that haemodialysis (HD) was not meeting their health expectations and demonstrated a general willingness to utilise palliative care if it would reduce suffering.

Conclusions: This study has shown that individuals with ESKD or their informal caregivers would consider palliative care services, if available. It paves the way for discussions about palliative care for ESKD to begin across renal centres within Ghana and other similar settings. Exploring perspectives of clinicians in such settings could inform strategies on how to implement palliative care for ESKD management in such settings.
\end{abstract}

Keywords: End-stage kidney disease, Palliative care, Conservative management, Haemodialysis, Ghana, Africa

\section{Background}

Palliative care for ESKD has been defined as "a transition from a conventional disease-oriented focus on dialysis as a rehabilitative treatment to an approach prioritizing comfort and alignment with preferences and goals of care to improve quality of life and reduce symptom burden" $[1,2]$. It comprises interventions that focus on

\footnotetext{
* Correspondence: guardian2405@yahoo.com

2Department of Nursing, Kwame Nkrumah University of Science and Technology, Kumasi, Ghana

Full list of author information is available at the end of the article
}

slowing the deterioration of kidney function, minimising the risk of adverse events, shared decision-making, active symptom management, detailed communication, including advance care planning, psychological, social and family support, and cultural and spiritual care, but does not include RRT [3-5]. The focus is on improving the quality of life of individuals with ESKD, in line with their values and goals, rather than merely extending their life $[4,6-8]$. This is increasingly becoming an accepted treatment choice and is highly recommended for individuals in whom renal replacement therapy (RRT) may 
offer little or no significant difference in terms of survival or quality of life $[3,4,6,9-14]$. Indeed, the World Health Organization [15] classifies ESKD among diseases that would benefit from palliative care.

Individuals with ESKD, cared for in renal centres where palliative care services are well-established, choose palliative care more often than centres without palliative care services $[2,16]$. It has been reported that individuals with ESKD would prefer to be given adequate information about the condition and their treatment options, including palliative care, at an earlier stage of the disease [17]. Yet, palliative care for managing ESKD is limited in several countries because of inadequate well-trained palliative care clinicians and poor access to palliative care services $[4,7]$. This is, especially, more profound in lower- and middle-income countries (LMICs) where financial, geographical and infrastructural challenges affect the provision of efficient renal services [18-22]. Inadequate information provision and delayed initiation of discussions on palliative care also remain key barriers to its utilisation as a treatment option for ESKD [2, 17, 23, 24]. Informal caregivers of individuals with ESKD, mainly relatives and friends, may also discourage clinicians' efforts at providing open and honest information about palliative care services [25].

Ghana is noted to have made improvements in the provision of palliative care services, being ranked 8th in Africa [26-28]. However, like in other African countries, palliative care largely focuses on HIV and cancer-related diagnoses $[20,28]$. There are no established pathways to palliative care for ESKD management, and the subject of death is rarely broached in discussions between clinicians and patients [18]. This study, therefore, explored the perceptions of individuals with ESKD and their informal caregivers on palliative care as a treatment option of the disease in Ghana.

\section{Methods}

\section{Research setting}

Ghana has inadequate renal services, with fifteen renal centres all located in five out of the sixteen administrative regions of the country [29]. These centres are managed by a few nephrologists, nephrology trainees, consultant physicians, specialist physicians, medical officers and, largely, by nurses who are trained-on-the-job $[18,29]$. Payment for the treatment of ESKD is mainly made out-of-pocket by patients or their significant others in Ghana as the National Health Insurance Scheme (NHIS) does not cover the treatment costs [18, 22, 29]. This results in only a few patients with ESKD being able to initiate and sustain treatment, and the increased tendency of reducing the frequency of dialysis, withdrawing from treatment and/or pursuing other forms of treatment outside biomedicine [18, 30].
This study was conducted in two renal centres that offer standard conservative care to individuals with ESKD who opt for it, including the treatment of anaemia, management of hypertension, pain as well as dietary and fluid management approaches, similar to other established renal centres [22, 31]. Although there are a few specialist palliative care services in the country, these are largely utilised by patients with advanced types of cancers and largely inaccessible to a majority of the citizenry owing to costs $[22,28]$.

\section{Study design, sampling and data collection}

This was a qualitative study, utilizing the phenomenological approach as it focussed on the lived experiences of individuals with ESKD and their informal caregivers and their perceptions about palliative care [32, 33]. The study targeted individuals with ESKD receiving haemodialysis at the two renal centres as well as their informal caregivers. A purposive sampling technique was employed for this study. After administrative approval was given, CS-W was introduced to eligible participants in both renal centres by the respective nurses-in charge to discuss the objectives of the study and their possible inclusion. Those who agreed confirmed their participation by signing or thumb-printing the consent form before being interviewed by CS-W. All those who were approached agreed to be part of the study.

Data for this study was collected through individual, face-to-face, semi-structured interviews. Each renal centre provided an office where the interviews were conducted, with only CS-W and the interviewee present in the office during each interview session. Two separate written interview guides were employed, one for the individual with ESKD and the other for informal caregivers to ensure comprehensive accounts from each interview session. Each interview guide was evaluated after the first session to ensure their accuracy, understandability, and appropriateness for this study, and to serve as a pilot test. There were no repeat interviews. Interview sessions lasted between 30 and $90 \mathrm{~min}$ and each was recorded using a digital audio-recording device. Field notes were written after each interview session to provide detailed observations and mannerisms that were not captured through the audio-recording. All audio-recordings were transcribed for data analysis. Two of the interview sessions were conducted in Twi, a popular Ghanaian dialect, and these were translated by CS-W. EAB and an independent researcher who are both fluent in the Twi and English languages verified the accuracy of the translation.

\section{Data processing and analysis}

All interviews were transcribed after each session. NVivo 10 software was used to manage and organize the data. 
Data collection and analysis occurred simultaneously, with the Colaizzi method [34, 35] guiding the analysis. All transcripts were proofread while listening to the audio recordings to ensure accuracy. Eleven participants agreed to look at their respective transcripts for comments and possible corrections and deletion of personal information - all were happy with the transcript and had no changes to be made. All transcripts were read multiple times and coded independently by CS-W and EAB. The field notes were also read to aid the contextualisation of various participant accounts during analysis. Significant statements about participants' experiences with management of ESKD and their perceptions of palliative care were extracted from their respective transcripts and meanings formulated from these statements. Each participant's experiences and perceptions were studied separately and then compared across transcripts. Both authors examined the data and used codes, patterns, and themes to classify them, meeting frequently to discuss emerging themes and agreeing on those that needed further exploration in subsequent interviews. These meetings continued until both authors agreed that themes had been adequately explored for the purpose of the study and ended data collection [36].

\section{Ethical considerations}

All participants gave their consent, either by signing or thumb-printing an informed consent form before participating in the study. Ethics approval (ID No: UCCIRB/CHAS/2015/105) was obtained from the Institutional Review Board of the University of Cape Coast, Ghana before data collection commenced. Participants were assured of confidentiality and anonymity, and their names and other personal identifiers have been replaced with pseudonyms in this paper to ensure this.

\section{Trustworthiness}

Data was collected from two renal centres as well as from two sources as a way of achieving triangulation and, in effect, ensuring credibility [37]. Also, member checks allowed participants to correct errors to ensure credibility [38, 39]. In this study, participants who were contacted did not find any errors or need for additional information. Both researchers coded and analysed the data independently, meeting to compare outcomes and resolve differences. Interpretation of data was supported by direct quotes from participants to enhance credibility and confirmability of the study findings [40-42]. Transferability has been enhanced by providing an in-depth description of the population and the context of the study [41]. This report has been guided by the Consolidated Criteria for Reporting Qualitative Research [43].

\section{Reflexivity}

In qualitative studies, the researcher becomes the instrument and is intimately involved in data collection and analysis. It was, therefore, important to reflect upon biases the researcher may have, a term called reflexivity [40]. CS-W has over 10 years' worth of experience in the management of ESKD. She is a nurse educator and served as a member of the palliative care team in her hospital. EAB has served as a nurse educator in Ghana for 9 years. He has a keen interest in enhancing the quality of life as well as decisionmaking experiences of individuals with ESKD. These potential biases were taken into consideration while collecting and analysing the data.

\section{Results}

Fifteen participants, comprising nine individuals with ESKD (patient-participants) receiving haemodialysis and six informal caregivers were included in this study. The sample size was determined after achieving data saturation [40]. Seven of the patient-participants were male while the remaining two were female. Duration on haemodialysis ranged from 5 months to 5 years. The youngest patient-participant was 20 years old while the oldest was 65 years old. Four of the six informal caregivers were female, and all were closely related to the patients with ESKD. Details of all participants have been provided in Table 1.

Three main themes were derived from the analysis of the data - motivation for initiating haemodialysis, facing realities of haemodialysis, and considering palliative care. Table 2 provides a summary of these themes and their sub-themes. Each of these three themes has been presented below, with relevant quotations from patientparticipants, and from informal caregivers to corroborate statements from patient-participants.

\section{Motivation for initiating haemodialysis}

Analysis of data showed that two main factors served as motivation for haemodialysis initiation - facing lifethreatening prognosis and mistaken expectations of a cure. The sub-theme 'facing life-threatening prognosis' described participants' expression of a full realisation that ESKD is life-threatening, especially without any form of RRT. This was mainly as a result of the clinical manifestations experienced and information gained from the renal centre. Others were also as a result of the poor prognosis of other patients with ESKD that they had met at the renal centre.

"It [ESKD] puts you in a state of fear because of the breathlessness, and blood issues [anaemia] - will I wake up the next day?" (Daniel, ESKD patient). 
Table 1 Characteristics of study Participants

\begin{tabular}{|c|c|c|c|}
\hline \multicolumn{4}{|c|}{ Details of patient participants } \\
\hline Name & $\begin{array}{l}\text { Age range } \\
\text { (years) }\end{array}$ & $\begin{array}{l}\text { Duration on } \\
\text { haemodialysis }\end{array}$ & Comorbidity \\
\hline Michael & $61-65$ & 5 months & $\begin{array}{l}\text { Hypertension, } \\
\text { diabetes mellitus }\end{array}$ \\
\hline David & $18-25$ & 5 months & None \\
\hline Peter & $61-65$ & 3 years & $\begin{array}{l}\text { Hypertension, } \\
\text { diabetes mellitus }\end{array}$ \\
\hline Martha & $26-30$ & 3 years & None \\
\hline Richard & $51-55$ & 3 years & $\begin{array}{l}\text { Hypertension, } \\
\text { diabetes mellitus }\end{array}$ \\
\hline Daniel & $46-50$ & 3 years & Hypertension \\
\hline Sandra & $36-40$ & 8 months & Hypertension \\
\hline Paul & $66-70$ & 3 years & $\begin{array}{l}\text { Hypertension, } \\
\text { diabetes mellitus }\end{array}$ \\
\hline Raymond & $56-60$ & 5 years & Hypertension \\
\hline \multicolumn{4}{|c|}{ Details of informal caregivers } \\
\hline Name & Age (years) & & $\begin{array}{l}\text { Relationship to ESKD } \\
\text { patient }\end{array}$ \\
\hline Gloria & $51-55$ & & Mother \\
\hline Margaret & $46-50$ & & Mother \\
\hline Doreen & $51-55$ & & Wife \\
\hline Douglas & $31-35$ & & Brother \\
\hline Paulina & $26-30$ & & Sister \\
\hline Eric & $18-25$ & & Nephew \\
\hline
\end{tabular}

"Yes, we think it can cause her death. Many times, she cannot breathe at night. All the time she needs to be transfused. Looking at how emaciated and the suffering she is going through I do not doubt that this will be her cause of death ... I will not be surprised" (Gloria, caregiver).

Some participants also started haemodialysis, hoping that a series of sessions would cure the disease. This mistaken expectation of a cure was the driving force for most of the initial decisions about treatment.

Table 2 Themes and sub-themes

\begin{tabular}{ll}
\hline Themes & Sub-themes \\
\hline Motivation for initiating & Facing life-threatening prognosis \\
Facmodialysis & $\begin{array}{l}\text { Mistaken expectations of cure } \\
\text { Faning realities of haemodialysis }\end{array}$ \\
& $\begin{array}{l}\text { Finaemodialysis } \\
\text { Becoming a burden to family }\end{array}$ \\
& Worsening quality of life \\
Considering palliative care & Death is inevitable \\
& Desiring dignified death \\
\hline
\end{tabular}

"I thought it [haemodialysis] was only for a few sessions and I will no longer require the treatment" (Michael, ESKD patient).

"Our understanding was that the haemodialysis is going to cure her of [the] symptoms she is experiencing" (Gloria, caregiver).

\section{Facing realities of haemodialysis}

Participants generally re-examined their health expectations and pondered the worth of haemodialysis, with its associated challenges, after receiving the treatment for some time. The theme 'facing realities of haemodialysis' describes this phase for participants. Expectations of haemodialysis were modified to the point where participants now hoped that their clinical manifestations would be as minimal as possible. Unfortunately, many participants felt that these modified expectations were also difficult to achieve. Some patient-participants reported that they had not noticed any improvements in their health status or quality of life even though they had been on haemodialysis for some time.

"Sometimes I have swollen leg; you can't know where it comes from ... I vomit, I go to the toilet [diarrhoea], and these are abnormal things that will not happen to any normal human being. Even though I'm doing the haemodialysis, these continue to come" (Peter, ESKD patient).

The burden of living with ESKD, including changes in health status and continuously raising large sums to finance their treatment but with little to no improvements led to feelings of despair among patient-participants. Indeed, they reported using all resources available to them to pursue treatment. Patient-participants also felt that they had become a burden to their significant others because they needed their assistance in performing activities of daily living, visiting the renal centre, or paying for the haemodialysis costs.

"They are fed up with me, they come with me to haemodialysis but they complain all the time, you see they are tired of following me here and there" (David, ESKD patient).

Informal caregivers reiterated the concerns about the realities of having their family member on haemodialysis and how onerous it is for the entire family.

"There are challenges because haemodialysis is costly. Everything is cash-and-carry and you are expected to pay without the National Health Insurance Scheme, not to talk about the cost of the 
[erythropoietin] injection, transportation and long hours on the machine, it is a worry" (Douglas, caregiver).

The informal caregivers also corroborated the views of patient-participants that haemodialysis was not offering any improvements in their quality of life or health status.

"She has never been well. Not a single day will this woman [patient] say 'I feel well'. After six months of haemodialysis, there are no signs of her getting well. It is very frustrating" (Paulina, caregiver).

This led to the next theme describing participants' perceptions regarding death and their prevailing circumstances surrounding treatment with haemodialysis.

\section{Considering palliative care}

Participants perceived palliative care as a means to provide relief from pain and other symptoms, ensuring that death does not come through endless suffering. Participants generally perceived death as an event that befalls all mankind and preferred not to expend all their resources on haemodialysis, cognisant of the inevitability of death and the devastating effect that their continuous utilisation of haemodialysis could have on their family. They also believed that, through palliative care, they could avoid or control suffering before death.

"I will opt for palliative care if that service is available for me so that I will not suffer but die peacefully" (Michael, ESKD patient).

Generally, informal caregivers were also of the view that if haemodialysis was not meeting their expectations of improved quality of life for their relatives nor guaranteeing survival, then they would not be reluctant to choose palliative care if the service is available.

"If we know the person will die eventually, I think she does not need to go through all these and lose [her] life. For me, I think that if the person cannot afford the haemodialysis, palliative care should be an option" (Gloria, caregiver).

Some patient-participants advocated that palliative care should be implemented and awareness created to enhance choosing it as an alternative or alongside haemodialysis during decision-making on treatment.

"Yes, in fact, please do that (implement palliative care). Life continues even after death, that's our belief. So, if I'm not getting well via the haemodialysis and somebody has time to talk to me, discuss my problems and spiritual wellbeing, why not?" (Peter, ESKD patient).

For relatively younger individuals with ESKD, however, caregivers felt uneasy about being introduced to palliative care. Yet, the belief that death is inevitable made them do all that they could in order not to appear nonsupportive of their relative.

"It [palliative care] can help but can you look at a young man like this one to die? What can we say? If it is the will of God, little can we do but we wish we can support him ... in that case if anything happens, you know it is the will of God" (Margaret, caregiver).

\section{Discussion}

This study aimed at exploring the perceptions of participants on palliative care as a treatment option for ESKD in Ghana. Many participants did not know much about the chronic and potential terminal nature of ESKD at the time of diagnosis and so were expectant of a cure when initiating treatment. Expectations of a cure around the time when treatment of ESKD is initiated has already been reported in Ghana [18] so this was, somewhat, not surprising. However, being on treatment for some time and experiencing symptoms associated with the disease made them perceive death as a real possibility. It is wellknown that ESKD is a life-threatening condition and those living with it confront mortality as part of their daily experiences [44], and personal or vicarious experiences of clinical manifestations of ESKD led participants of this study to confront their mortality. Our study found that during such moments, deeper meanings about death were reflected upon. Comments that implied that death is part of life reflect their effort to 'normalise' death as a potential outcome of the disease. This did not always suggest acceptance of their prognosis though, especially as they had not had formal discussions with their clinicians about their prognosis and palliative care.

Palliative care is recommended for patients with ESKD in whom RRT would not offer survival benefits or improved quality of life. These are usually the very elderly, those with comorbidities as well as those who initiate RRT within three months of diagnosis as a result of late presentation [3, 4, 6, 9-13]. For such individuals, palliative care ensures that they receive quality care as they near the end of life. Although patients with ESKD are generally young in the Ghanaian setting, late presentation, poor functional status and high mortality rates associated with ESKD imply that many could benefit from palliative care services if this choice was to be available $[9,18,19,22,45,46]$. The treatment choices of the Ghanaian patient with ESKD are limited in so many 
ways when survival is the expected outcome, unlike in many high-income countries where there is a menu of life-saving treatment choices available to the patient [18, $47,48]$. Despite the modality constraints, the initial drive to preserve life led participants to initiate haemodialysis until they realised that sustainability is nearly impossible or comes with its daunting adjustments.

Studies on palliative care for ESKD report that this treatment choice is made because individuals do not want to burden their families, feel neglected, experience a deterioration of their quality of life, experience acute medical complications, or when they are unsure of good prognosis $[7,44,49,50]$. The desire not to burden others also seemed to play a role in making individuals living with ESKD in this study consider accepting palliative care. However, consideration for palliative care mainly stemmed from realising that there is no certainty of a good prognosis, coupled with a general deterioration of their quality of life. The impact of haemodialysis on individuals' or their families' finances also had a stronger role to play in their search for a different treatment option. Indeed, there are instances where comprehensive conservative care becomes the only option in the face of resource constraints or limited access to renal replacement therapy $[5,14]$. However, comprehensive conservative care of patients with ESKD must not be perceived as a low-cost option in place of well-developed RRT services in LMICs but as a component of integrated and patient-centred care for those with the disease $[10,51]$. This study noted that participants had not been extensively engaged in discussions regarding end-of-life care. An improvement in the provision of information on prognosis and available support is a key strategy in enhancing the utilisation of comprehensive conservative care, including palliative care [10]. Indeed, the limitations around efficient renal services in LMICs cannot be understated, including unavailability of appropriately-trained clinicians to deliver specialist care as required. Unavailability of an established palliative care pathway for the management of ESKD means that death could not even be managed in a more 'dignified' way for those who could not benefit from RRT. Yet, this study brings to the fore the longing need for palliative care as a potential treatment choice that could be made by individuals with ESKD and their families in Ghana. It may well be that with improvements in access and dialysis outcomes, patients' views might be completely different. However, palliative care services should be developed for patients with multiple comorbidities or at the end of their lives in whom dialysis poses a risk of being a futile therapy [14]. Timing for initiating a discussion on palliative care is essential as participants considered it only after being on haemodialysis for a while.
The support of informal caregivers is instrumental in decisions regarding the treatment of patients with ESKD $[52,53]$. Indeed, informal caregivers of patients with ESKD have their usual routines disrupted in many unexpected ways as a result of the disease, including having to accompany them to the renal centre and dealing with untoward psychological responses of patients to the disease and its treatment such as depression [53]. Yet, informal caregivers, sometimes, pressurise patients with ESKD to initiate and sustain RRT, with the belief that patients could get better with time, especially when patients are relatively young $[25,54]$. Our study found that, in some instances, informal caregivers did everything in their power to ensure that the patient is sustained on treatment for as long as possible. The realities of living with the disease, however, led to a change of perspective and a preference for palliative care services.

\section{Study strengths and limitation}

The phenomenological approach employed has given voice to those confronting mortality daily in an LMIC setting as a result of ESKD. Although the findings cannot be generalised, like all other qualitative study approaches, the study has raised insightful issues that could be explored further in other renal centres within the country and other similar settings. It paves the way for discussions about palliative care for ESKD to begin across renal centres within Ghana and other similar settings.

\section{Conclusions}

This study has shown that individuals with ESKD or their informal caregivers would consider palliative care services, if available. Indeed, as has always been advocated, primary prevention of ESKD, including meticulous management of ESKD precursor conditions is the way to go, especially in resource-constrained settings. Notwithstanding, a reasonable number of individuals who have already developed ESKD stand to benefit from integrated renal services, including palliative care. Seeking the opinions of clinicians in such settings would be a way to bring their perspectives about palliative care to the fore.

\section{Supplementary information}

Supplementary information accompanies this paper at https://doi.org/10. 1186/s12904-020-00640-y.

Additional file 1. Interview Guide

\section{Abbreviations}

ESKD: End-stage kidney disease; LMICs: Lower- and middle-income countries; RRT: Renal replacement therapy

\section{Acknowledgements}

The authors would like to express their gratitude to all participants who willingly shared their experiences in this study. The authors also 
acknowledge the support of Prof. Funmilayo Okalanwon and Dr. Jerry Ninnoni all of the School of Nursing and Midwifery, University of Cape Coast, Ghana during the conduct of this study.

\section{Authors' contributions}

Both authors conceptualised the study. CS-W collected data for this study. Both CS-W and EAB were involved in the analysis and interpretation of the data. Both authors drafted the manuscript and approved the final draft of this paper.

\section{Funding}

This research received no grant from any funding agency in the public commercial, or not-for-profit sectors.

\section{Availability of data and materials}

Data can be made available upon reasonable request to the corresponding author so long as it complies with regulations of the institutional review board.

\section{Ethics approval and consent to participate}

Ethics approval (ID No: UCCIRB/CHAS/2015/105) was obtained from the Institutional Review Board of the University of Cape Coast, Ghana before data collection commenced. Eligible participants were given information about the study in either the English language or Twi, based on their preference, as a way of obtaining their informed consent. Participation was entirely voluntary and only individuals who gave their consent, either by signing or thumb-printing an informed consent form participated in the study. Thum-printing was in line with expectations of the institutional review board for participants who could not sign the consent form. Eligible participants were assured that non-participation will not affect the care they receive from the renal centres in any way. Participants' names and other personal identifiers have been replaced with pseudonyms to maintain confidentiality and anonymity.

\section{Consent for publication}

Not applicable.

\section{Competing interests}

The authors declare that there is no conflict of interest.

\section{Author details}

'Department of Nursing, Garden City University College, Kumasi, Ghana ${ }^{2}$ Department of Nursing, Kwame Nkrumah University of Science and Technology, Kumasi, Ghana.

\section{Received: 1 May 2020 Accepted: 16 August 2020}

Published online: 20 August 2020

\section{References}

1. Grubbs V, Moss AH, Cohen LM, Fischer MJ, Germain MJ, Jassal SV, et al. A palliative approach to Dialysis care: a patient-centered transition to the end of life. Clin J Am Soc Nephrol. 2014;9(12):2203.

2. Axelsson L, Benzein E, Lindberg J, Persson C. End-of-life and palliative care of patients on maintenance hemodialysis treatment: a focus group study. BMC Palliative Care. 2019;18(1):89

3. Johnston S, Noble H. Factors influencing patients with stage 5 chronic kidney disease to opt for conservative management: a practitioner research study. J Clin Nurs. 2012:21(9-10):1215-22.

4. Morton RL, Webster AC, McGeechan K, Howard K, Murtagh FE, Gray NA, et al. Conservative management and end-of-life care in an Australian cohort with ESRD. Clin J Am Soc Nephrol. 2016;11(12):2195-203.

5. Murtagh FEM, Burns A, Moranne O, Morton RL, Naicker S. Supportive care: comprehensive conservative Care in end-Stage Kidney Disease. Clin J Am Soc Nephrol. 2016;11(10):1909.

6. O'Connor NR, Kumar P. Conservative management of end-stage renal disease without dialysis: a systematic review. J Palliat Med. 2012;15(2):228-35.

7. Chen JC-Y, Thorsteinsdottir B, Vaughan LE, Feely MA, Albright RC, Onuigbo $\mathrm{M}$, et al. End of life, withdrawal, and palliative care utilization among patients receiving maintenance hemodialysis therapy. Clin J Am Soc Nephrol. 2018;13(8):1172-9.
8. Scherer JS, Wright R, Blaum CS, Wall SP. Building an Outpatient Kidney Palliative Care Clinical Program. J Pain Symptom Manag. 2018;55(1):108-16 e2.

9. Davison R, Sheerin NS. Prognosis and management of chronic kidney disease (CKD) at the end of life. Postgrad Med J. 2014;90(1060):98-105.

10. Harris DC, Davies SJ, Finkelstein FO, Jha V, Donner J-A, Abraham G, et al. Increasing access to integrated ESKD care as part of universal health coverage. Kidney Int. 2019;95(4):S1-S33.

11. Dionne JM, d'Agincourt-Canning L. Sustaining life or prolonging dying? Appropriate choice of conservative care for children in end-stage renal disease: an ethical framework. Pediatr Nephrol. 2015;30(10):1761-9.

12. Noble $\mathrm{H}$. An aging renal population-is dialysis always the answer? Br J Nurs. 2011;20(9):545-7.

13. Douglas A. Palliative care for patients with advanced chronic kidney disease. J Royal Coll Phys Edinburgh. 2014;44(3):224-31.

14. Davison SN, Levin A, Moss AH, Jha V, Brown EA, Brennan F, et al. Executive summary of the KDIGO controversies conference on supportive Care in Chronic Kidney Disease: developing a roadmap to improving quality care. Kidney Int. 2015;88(3):447-59

15. World Health Organization. Palliative Care, Factsheet No 4022015 [Available from: http://www.who.int/mediacentre/factsheets/fs402/en/.

16. Tonkin-Crine S, Okamoto I, Leydon GM, Murtagh FE, Farrington K, Caskey F, et al. Understanding by older patients of dialysis and conservative management for chronic kidney failure. Am J Kidney Dis. 2015;65(3):443-50.

17. Lazenby S, Edwards A, Samuriwo R, Riley S, Murray MA, Carson-Stevens A. End-of-life care decisions for haemodialysis patients - 'we only tend to have that discussion with them when they start deteriorating'. Health Expect. 2017;20(2):260-73.

18. Boateng EA, East $L$, Evans $C$. Decision-making experiences of patients with end-stage kidney disease (ESKD) regarding treatment in Ghana: a qualitative study. BMC Nephrol. 2018;19(1):1-12.

19. Ashuntantang G, Osafo C, Olowu WA, Arogundade F, Niang A, Porter J, et al. Outcomes in adults and children with end-stage kidney disease requiring dialysis in sub-Saharan Africa: a systematic review. Lancet Glob Health. 2017:5(4):e408-e17.

20. Bates MJ, Chitani A, Dreyer G. Palliative care needs of patients living with end-stage kidney disease not treated with renal replacement therapy: an exploratory qualitative study from Blantyre, Malawi. Afr J Prim Health Care Fam Med. 2017:9:1-6.

21. Ddungu $\mathrm{H}$. Palliative care: what approaches are suitable in developing countries? Br J Haematol. 2011:154(6):728-35.

22. Tannor EK, Norman BR, Adusei KK, Sarfo FS, Davids MR, Bedu-Addo G. Quality of life among patients with moderate to advanced chronic kidney disease in Ghana - a single Centre study. BMC Nephrol. 2019;20(1):122.

23. Mcllfatrick S, Hasson F, McLaughlin D, Johnston G, Roulston A, Rutherford L, et al. Public awareness and attitudes toward palliative care in Northern Ireland. BMC Palliat Care. 2013;12(1):34.

24. Mcllfatrick S, Noble H, McCorry NK, Roulston A, Hasson F, McLaughlin D, et al. Exploring public awareness and perceptions of palliative care: a qualitative study. Palliat Med. 2014:28(3):273-80.

25. Noble H, Price JE, Porter S. The challenge to health professionals when carers resist truth telling at the end of life: a qualitative secondary analysis. J Clin Nurs. 2014;24(7-8):927-36.

26. Connor S, Bermedo MS. Global atlas of palliative care at the end of life Geneva, Switzerland/London, UK: Worldwide Palliative Care Alliance; World Health Organization; 2014 [Available from: https://www.who.int/nmh/ Global_Atlas_of_Palliative_Care.pdf.

27. Rhee JY, Garralda E, Namisango E, Luyirika E, De Lima L, Powell RA, et al. An analysis of palliative care development in Africa: a ranking based on regionspecific macroindicators. J Pain Symptom Manag. 2018;56(2):230-8.

28. Ofosu-Poku R, Owusu-Ansah M, Antwi J. Referral of patients with nonmalignant chronic diseases to specialist palliative care: a study in a teaching Hospital in Ghana. Int J Chronic Dis 2020;2020.

29. Tannor E, Awuku Y, Boima V, Antwi S. The geographical distribution of dialysis services in Ghana. Renal Replacement Ther. 2018;4(1):3.

30. Jha V, Arici M, Collins AJ, Garcia-Garcia G, Hemmelgarn BR, Jafar TH, et al. Understanding kidney care needs and implementation strategies in lowand middle-income countries: conclusions from a "kidney disease: improving global outcomes" (KDIGO) controversies conference. Kidney Int 2016;90(6):1164-74. 
31. Pommer W, Wagner S, Thumfart J. Conservative care, Dialysis withdrawal, and palliative care: results from a survey of a non-profit Dialysis provider in Germany. Kidney Blood Press Res. 2019;44(2):158-69.

32. Starks H, Trinidad SB. Choose your method: a comparison of phenomenology, discourse analysis, and grounded theory. Qual Health Res. 2007;17(10):1372-80

33. Pringle J, Drummond J, McLafferty E, Hendry C. Interpretative phenomenological analysis: a discussion and critique. Nurse researcher. 2011;18(3):20-4.

34. Colaizzi PF. Psychological research as the phenomenologist views it. In: Vale R, King M, editors. Existential-phenomenological alternatives for psychology. New York: Oxford University Press; 1978.

35. Wirihana L, Welch A, Williamson M, Christensen M, Bakon S, Craft J. Using Colaizzi's method of data analysis to explore the experiences of nurse academics teaching on satellite campuses. Nurse Res. 2018;25(4):30.

36. O'reilly M, Parker N. 'Unsatisfactory saturation': a critical exploration of the notion of saturated sample sizes in qualitative research. Qual Res. 2013;13(2): 190-7.

37. Connelly LM. Trustworthiness in qualitative research. Medsurg Nurs. 2016; 25(6):435-7.

38. Guba E, Lincoln Y. Competing paradigms in qualitative research. In: Denzin N, Lincoln Y, editors. Handbook of qualitative research. California: Sage; 1994. p. 105-17.

39. Thomas DR. Feedback from research participants: are member checks useful in qualitative research? Qual Res Psychol. 2017;14(1):23-41.

40. Polit DF, Beck CT. Nursing research: generating and assessing evidence for nursing practice. 9 ed. Philadelphia: Lippincott Williams \& Wilkins; 2012.

41. Noble $\mathrm{H}$, Smith J. Issues of validity and reliability in qualitative research. Evid Based Nurs. 2015;18(2):34-5.

42. Korstjens I, Moser A. Series: practical guidance to qualitative research. Part 4 trustworthiness and publishing. Eur J Gen Pract. 2018;24(1):120-4.

43. Tong A, Sainsbury P, Craig J. Consolidated criteria for reporting qualitative research (COREQ): a 32-item checklist for interviews and focus groups. Int Qual Health Care. 2007;19(6):349-57.

44. Morton R, Tong A, Howard K, Snelling P, Webster A. The views of patients and carers in treatment decision making for chronic kidney disease: systematic review and thematic synthesis of qualitative studies. BMJ. 2010; 340(7742):1-11.

45. Luyckx VA, Miljeteig I, Ejigu AM, Moosa MR. Ethical challenges in the provision of Dialysis in resource-constrained environments. Semin Nephrol. 2017;37(3):273-86.

46. Eghan BA, Amoako-Atta K, Kankam CA, Nsiah-Asare A. Survival pattern of hemodialysis patients in Kumasi, Ghana: a summary of forty patients initiated on hemodialysis at a new hemodialysis unit. Hemodial Int. 2009; 13(4):467-71.

47. Harwood L, Clark AM. Understanding pre-dialysis modality decision-making: a meta-synthesis of qualitative studies. Int J Nurs Stud. 2013;50(1):109-20.

48. Murray MA, Brunier G, Chung JO, Craig LA, Mills C, Thomas A, et al. A systematic review of factors influencing decision-making in adults living with chronic kidney disease. Patient Educ Couns. 2009;76(2):149-58.

49. Ashby M, Op't Hoog C, Kellehear A, Kerr PG, Brooks D, Nicholls K, et al. Renal dialysis abatement: lessons from a social study. Palliat Med. 2005;19(5): 389-96.

50. Tong A, Cheung KL, Nair SS, Kurella Tamura M, Craig JC, Winkelmayer WC. Thematic synthesis of qualitative studies on patient and caregiver perspectives on end-of-life care in CKD. Am J Kidney Dis. 2014;63(6):913-27.

51. Hole B, Hemmelgarn B, Brown E, Brown M, McCulloch MI, Zuniga C, et al. Supportive care for end-stage kidney disease: an integral part of kidney services across a range of income settings around the world. Kidney Int Suppl. 2020;10(1):e86-94.

52. Grubbs V, Tuot DS, Powe NR, O'Donoghue D, Chesla CA. Family involvement in decisions to forego or withdraw Dialysis: a qualitative study of nephrologists in the United States and England. Kidney Med. 2019;1(2): 57-64.

53. DePasquale N, Cabacungan A, Ephraim PL, Lewis-Boyér L, Powe NR, Boulware LE. Family members' experiences with dialysis and kidney transplantation. Kidney Med. 2019;1(4):171-9.

54. Sellars M, Clayton JM, Morton RL, Luckett T, Silvester W, Spencer L, et al. An interview study of patient and caregiver perspectives on advance care planning in ESRD. Am J Kidney Dis. 2018;71(2):216-24.

\section{Publisher's Note}

Springer Nature remains neutral with regard to jurisdictional claims in published maps and institutional affiliations.
Ready to submit your research? Choose BMC and benefit from:

- fast, convenient online submission

- thorough peer review by experienced researchers in your field

- rapid publication on acceptance

- support for research data, including large and complex data types

- gold Open Access which fosters wider collaboration and increased citations

- maximum visibility for your research: over $100 \mathrm{M}$ website views per year

At BMC, research is always in progress.

Learn more biomedcentral.com/submissions 